\title{
European nations launch tax attack on unhealthy foods
}

$\mathrm{G}$ oodbye pizza, burgers, chips, butter, soda pop, milk, cheese, pizza, bacon, Danish pastries and luxurious Hungarian dobostorta cake.

Hello dry toast and soy pudding.

The cynical might suggest that European governments are falling over one another to introduce fat taxes to help offset their staggering debt loads, but governments say they're rushing to introduce new levies on products high in saturated and trans fats, sugar and salts to reduce the burden of diabetes, cardiovascular and other chronic diseases caused by their populace's fondness for deep-fried chocolate bars and other treats that might just as well be piled directly upon bathroom scales.

Denmark, France and Hungary were among the nations moving over the course of the summer to introduce taxes on foods and beverages whose consumption is believed to pack on the pounds and drive up health care costs.

Hungary's new fat taxes are perhaps the most comprehensive, having been levied on foods with high fat, sugar, salt and caffeine content. The government also increased its tariffs on soda and alcohol. The value of the tax varies by product. For example, the added levy on soft drinks was $€ 0.016$ per litre. It was $€ 0.33$ per kilogram for prepackaged sweetened products, €0.67 per kilogram for salty snacks and $€ 0.84$ per litre for energy drinks.

Denmark targeted its attack on saturated fats, unveiling a levy of $€ 2.41$ per kilogram of saturated fat used in the production of a particular food. The effect is to levy a heavier tax on higher fat foods, such as hamburgers or butter (http://ec.europa.eu/enterprise/tris/pisa /app/search/index.cfm?fuseaction=get draft\&inum=1627030). The tax kicks in when the saturated fat content of a food product tops $2.3 \%$.

France soon got in on the act, announcing a new $€ 0.036$ per litre tax on sweetened drinks (www.sante.gouv.fr /des-mesures-qui-renforcent-notre-action

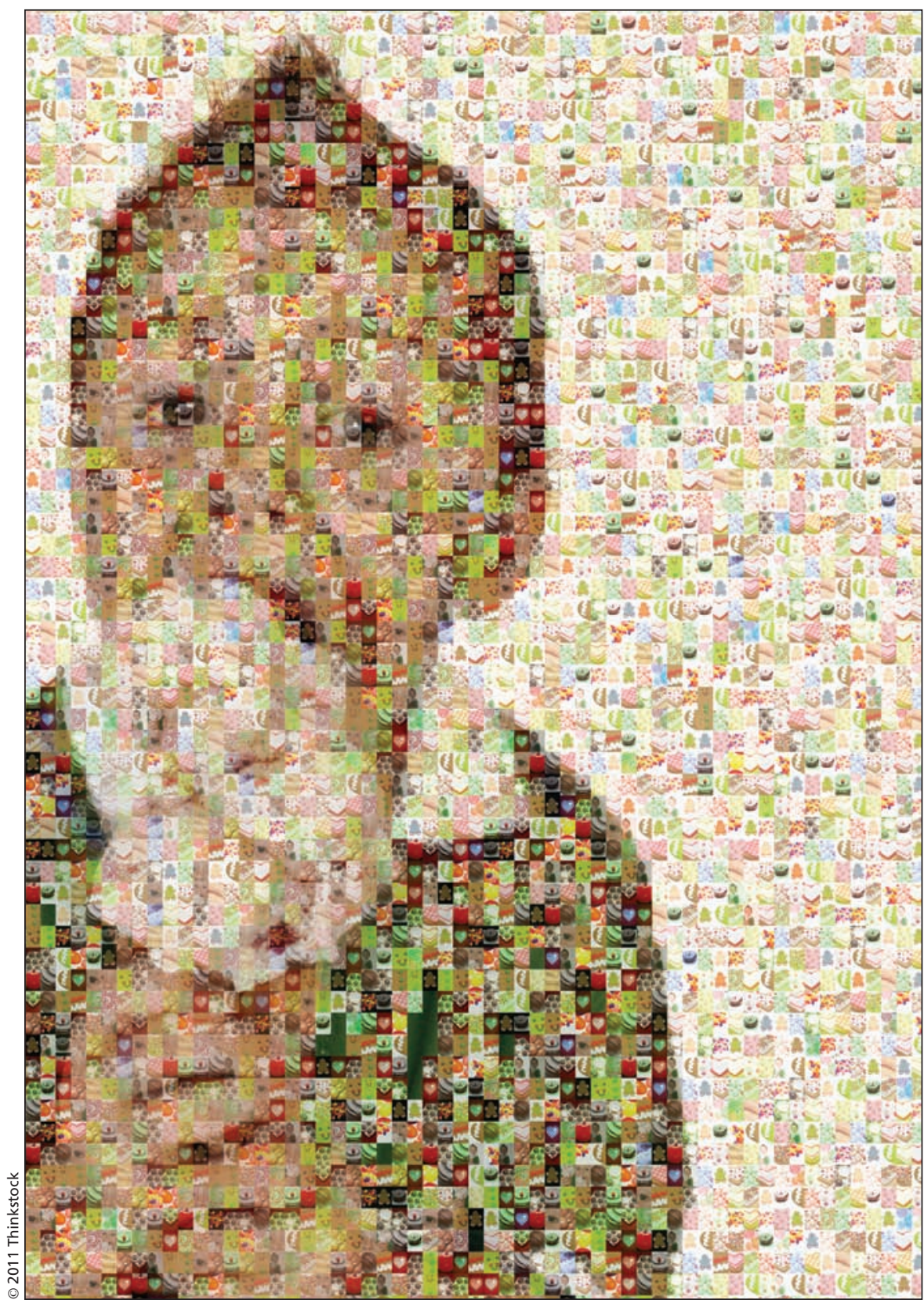

Roughly $15.5 \%$ of Europeans are obese, according to the Organisation for Economic Cooperation and Development. But that rate is lower than in Canada (16.5\%) and the United States (27.7\%).

-de-prevention-et-de-lutte-en-matiere-de -sante-publique.html). Sugar-free soft drinks, water and unsweetened fruit juices escape the levy, which is projected to bolster French coffers by about $€ 150$ million.

Romania, Finland and most recently the United Kingdom have indicated that they are considering a leap onto the fat tax express but there's no sign of any manner of European Union-wide levy.

Hungary's premium will garner a projected $€ 170$ million which the 
government says will be pumped into health care costs and lower obesity rates. According to the Organisation for Economic Co-operation and Development, $19.5 \%$ of adult Hungarians self-reported as being obese in 2009 , slightly higher than the $15.5 \%$ European average and the $16.5 \%$ rate of Canada, but below the $27.7 \%$ level of the United States (www .oecd.org/document/16/0,3343,en_2649 _34631_2085200_1_1_1_1,00.html).

The fat taxes are necessary as "the overall health status of the Hungarian population is very unsatisfactory compared to international standards and to the level that the country's socio-economic development would justify," the Hungarian government said in a statement announcing the taxes, according to Ildiko Kiss, an advisor to the Ministry of Natural Resources, which oversees health care in Hungary.
Public health advocates concur.

"There is substantial evidence in existence showing that taxation is very cost effective when it comes to tobacco and alcohol for both health and financial motives. Regarding food, fiscal measures need to encourage the consumption of healthy options and reduce unhealthy options on the market. The Organization for Economic Co-Operation and Development recently modeled the impact that taxation could have on reducing obesity," Monika Kosinska secretary general of the European Public Health Alliance, writes in an email.

According to that study, Obesity and the Economics of Prevention, fat taxes and similar "regulations and fiscal measures are more transparent and contestable interventions, although they hit all consumers indiscriminately, may be difficult to organise and enforce and may have regressive effects" (www.oecd.org/dataoecd/21 /19/46004918.pdf ).

But Kosinska says that European nations "simply cannot afford not to" introduce fat taxes.

Others say the solutions aren't so "simplistic."

"We need to take an ecological point of view and look seriously at all strategies, not just zero in on one or two simplistic solutions," Dr. Richard Roberts, president of the World Organization of Family Doctors and professor of family medicine at the University of Wiscon$\sin$ in Madison, writes in an email. "It's not just what we put in their mouth, it's also what food choices we have, what exercise opportunities we have, what daily routines we have, and so on." Tiago Villanueva MD, Lisbon, Portugal

CMAJ 2011. DOI:10.1503/cmaj.109-4031 